\title{
Assessing response to therapy in idiopathic pulmonary arterial hypertension: A consensus survey of Canadian pulmonary hypertension physicians
}

\author{
Adrienne E Borrie MSc, David N Ostrow MD FRCPC, Robert D Levy MD FRCPC, John R Swiston MD MPH FRCPC
}

AE Borrie, DN Ostrow, RD Levy, JR Swiston. Assessing response to therapy in idiopathic pulmonary arterial hypertension: A consensus survey of Canadian pulmonary hypertension physicians. Can Respir J 2011;18(4):230-234.

BACKGROUND: Many treatment options are now available for patients with idiopathic pulmonary arterial hypertension (IPAH). Data regarding the optimal combination of therapies are lacking, as is consensus on how to assess response to therapy and when to change therapeutic regimens. OBJECTIVES: To gather the opinions of Canadian pulmonary hypertension $(\mathrm{PH})$ experts regarding standard practice in the care of IPAH patients after therapy is initiated.

METHODS: Canadian PH physicians were surveyed using short questionnaires to assess their opinions and practices in the care of IPAH patients. A Delphi forecasting approach was used to gain consensus among Canadian physicians on the most important clinical parameters to consider when assessing patients after the initiation of therapy.

RESULTS: Twenty-six of 37 Canadian PH experts who were invited to participate completed the study. All endorsed the use of combination therapy for IPAH patients despite the lack of universal provincial coverage for this approach. By consensus, WHO functional class, 6 min walk distance and hospitalization for right heart failure were the most important clinical parameters. The most highly rated physical examination parameters were jugular venous pressure, peripheral edema, the presence of ascites and body weight.

CONCLUSIONS: The overall approach to care of IPAH patients is similar across PH centres in Canada. A limited number of clinical and physical examination parameters were considered to be most important to reassess patients after therapy is initiated. These parameters, along with definition of threshold values, will facilitate the development of standard practice guidelines for IPAH patients in Canada.

Key Words: Health survey; Pulmonary hypertension; Therapy

Dulmonary arterial hypertension (PAH) is a condition affecting 1 the lung microcirculation and is characterized by a progressive increase in pulmonary vascular resistance leading to right ventricular dysfunction, cardiopulmonary disability and premature death (1-3). $\mathrm{PAH}$ is defined hemodynamically as a resting mean pulmonary arterial pressure (mPAP) of greater than $25 \mathrm{mmHg}$ with a pulmonary capillary wedge pressure of lower than $15 \mathrm{mmHg}(1,4)$. When there is no identifiable cause for the development of $\mathrm{PAH}$, the disease is labelled idiopathic PAH (IPAH) (5).

While there is currently no cure for IPAH, medical advances in the field of pulmonary hypertension (PH) have led to the emergence of several treatment options for patients with IPAH aimed at slowing disease progression, improving symptoms and quality of life, and prolonging suvival (6). Three classes of medications have now been approved in Canada for the treatment of PAH: prostanoids (7), endothelin-1 receptor antagonists (ERAs) (8) and phosphodiesterase type 5 inhibitors (PDE5is) $(6,9,10)$. With the availability of multiple therapies, treatment of IPAH has become more complex. Attention is now being paid to treating patients earlier in the disease course, considering the use of multiple agents in combination, and changing
Évaluer la réponse à la thérapie en cas d'hypertension artérielle pulmonaire idiopathique : une enquête consensuelle auprès de médecins canadiens qui soignent l'hypertension pulmonaire

HISTORIQUE : De nombreuses possibilités thérapeutiques sont désormais offertes aux patients atteints d'hypertension artérielle pulmonaire idiopathique (HAPI). On ne possède ni données relatives à la thérapie d'association optimale, ni consensus sur l'évaluation de la réponse au traitement et sur le moment de modifier le schéma posologique.

OBJECTIFS : Colliger l'avis de spécialistes canadiens de l'hypertension pulmonaire (HP) quant aux pratiques standards de soins aux patients atteints d'HAPI après l'amorce du traitement.

MÉTHODOLOGIE : Au moyen d'une enquête par questionnaires courts, les chercheurs ont évalué les opinions et les pratiques des médecins canadiens soignant l'HP dans le cadre des soins aux patients atteints d'HAPI. Ils ont utilisé la méthode prévisionniste Delphi pour obtenir un consensus entre médecins canadiens à l'égard des principaux paramètres cliniques à envisager lors de l'évaluation des patients après l'amorce de la thérapie.

RÉSULTATS : Vingt-six des 37 spécialistes canadiens de l'HP invités à participer ont répondu à l'enquête. Tous ont avalisé l'utilisation d'une thérapie d'association pour les patients atteints d'HAPI, malgré l'absence de remboursement provincial universel à cet égard. Par consensus, la classe fonctionnelle de l'OMS, la distance de marche sur six minutes et l'hospitalisation consécutive à une insuffisance cardiaque droite représentaient les principaux paramètres cliniques. Les paramètres d'examen physique les mieux cotés étaient la pression veineuse jugulaire, l'œdème périphérique, la présence d'ascites et le poids.

CONCLUSIONS : La démarche globale des soins aux patients atteints d'HAPI est similaire entre les centres d'HP du Canada. Un nombre limité de paramètres d'examen clinique et physique étaient considérés comme les plus importants pour réévaluer les patients après l'amorce de la thérapie. Ces paramètres, de même que la définition des valeurs seuils, faciliteront la mise au point de lignes directrices sur les pratiques standards à l'intention des patients atteints d'HAPI au Canada.

therapeutic regimens based on clinical status and response to treatment (9). To some degree, the pharmacological advances in the treatment of IPAH have grown faster than our understanding of how to best use these therapies clinically. Data regarding the optimal combination of therapies are lacking, as is consensus on when or how to introduce multiple medications (6). Furthermore, despite the lack of evidence-based guidance, clinicians must decide when and how to reevaluate patients after the initiation of therapy, define what an adequate response to therapy is, and determine what to do when such a response is or is not achieved. The purpose of the present study was to survey the attitudes of Canadian physicians caring for patients with IPAH, and to generate a consensus opinion with regard to the methods of reassessment and goals after patients have been initiated on therapy.

\section{METHODS}

A list of PH experts was generated from a census of Canadian physicians who regularly prescribe bosentan (provided by Actelion Pharmaceuticals, Canada) as well as those known to be $\mathrm{PH}$ specialists affiliated with one of the 14 major PH centres in Canada and/or members of the Canadian Thoracic Society's Canadian Pulmonary Vascular

Division of Respiratory Medicine, University of British Columbia, Vancouver, British Columbia

Correspondence: Dr John R Swiston, Division of Respiratory Medicine, University of British Columbia, Vancouver General Hospital,

2775 Laurel Street, 7th Floor, Vancouver, British Columbia V5Z 1M9. Telephone 604-875-4111, fax 604-875-4695,

e-mailswiston@interchange.ubc.ca 
TABLE 1

Summary of survey participants

\begin{tabular}{lccc}
\hline Question & Surveys sent, $\mathbf{n}$ & Respondents, $\mathbf{n}$ & Response rate, \% \\
\hline Phase I & 37 & 26 & 70 \\
Phase II stem A & 37 & 26 & 70 \\
Phase II A1 & 36 & 22 & 61 \\
Phase II A2 & 22 & 22 & 100 \\
Phase II stem B & 36 & 22 & 61 \\
Phase II B1 & 22 & 22 & 100 \\
Phase II B2 & 23 & 22 & 96 \\
\hline
\end{tabular}

TABLE 2

Survey question 2: "How soon after initiation of therapy should patients be re-evaluated?"

\begin{tabular}{lc}
\hline WHO class & Months, mean \pm SD \\
\hline II & $3.73 \pm 1.55$ \\
III & $2.23 \pm 0.97$ \\
IV & $1.36 \pm 0.85$ \\
\hline
\end{tabular}

Diseases Committee. Invitations to participate in the study were sent by e-mail. The e-mail contained a description of the aims and scope of the study as well as a link to the web survey (Survey Monkey [www. surveymonkey.com]). Participation was voluntary and without compensation. All experts who were sent questionnaires were asked to opt out of the survey if they believed that they did not care for a sufficient number of $\mathrm{PH}$ patients to be able to provide an expert opinion. Those who did not respond to the survey were re-contacted by e-mail and encouraged to respond. Participants were blinded to the individual responses of other participants.

The survey was conducted between October 2008 and August 2009. Each physician received a sequential series of short questionnaires probing their opinions and practices regarding the care of IPAH patients. The complete survey is provided in Appendix 1. In the first phase of the survey (phase I) participants were asked several closed questions describing their basic approach to the management of IPAH patients after diagnosis and the initiation of therapy, particularly with regard to the timing and method of re-assessment and the approach to therapeutic decision making. For all questions, the physicians were asked to describe their preferred patient management strategy in a theoretical context of an absence of constraints of government or private health insurance formulary reimbursement restrictions.

In the second phase of the study (phase II stem A), participating physicians were asked which parameters they believed should be included as targets for therapy. Participants could provide as many parameters as they considered necessary. A common response to the first question was "physical examination". The investigator survey team did not believe that this response was specific enough to be clinically useful and, therefore, a second open-ended question was presented asking participants what specific findings on examination they believed were relevant (phase II stem B). For both questions, the responses of all participants were compiled. A subsequent questionnaire was sent listing all parameters that were previously described. Participants were asked to rate how important they believed each parameter was in the determination of an adequate response to therapy on a scale from 0 to 5 , with ' $O$ ' indicating that they did not believe that the parameter had any value in the routine evaluation of $\mathrm{PH}$ patients. No additional instructions were given on the rating scale. The ratings were collected and the mean response was calculated for each parameter. Using the Delphi consensus method (11), a final questionnaire was sent to the participants at which time the previous results were displayed so that each participant could view their own results as well as the mean and SD calculated from all participants. The participants were then asked to rate each parameter again, incorporating this new information. The mean and SDs for each parameter were then recalculated.

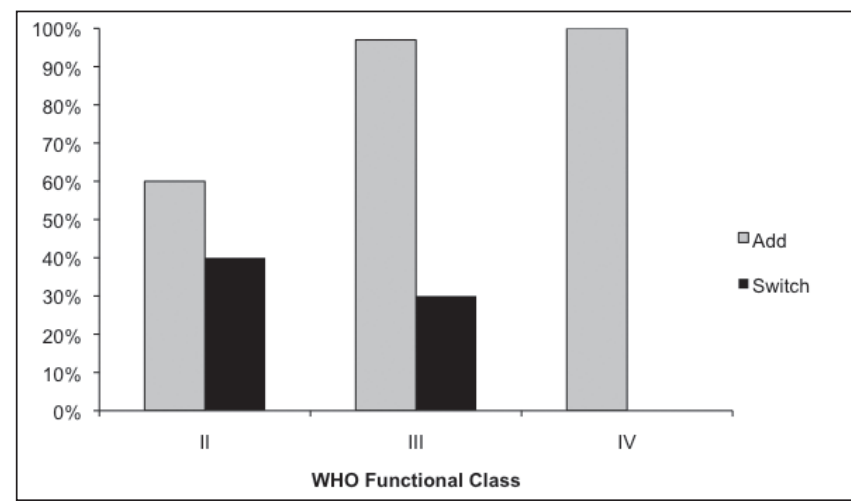

Figure 1) Survey question 5. "If your formulary did not play a role: when a patient is on oral monotherapy but is felt not to have had an adequate clinical response, would you routinely switch to an alternative oral agent or add an additional oral agent (assuming that the patient is tolerating the first drug without side effects)?" ( $n=26)$

\section{RESULTS}

Of the $37 \mathrm{PH}$ experts invited, 26 (70\%) participated in phase I of the survey and in generating clinical parameters in phase II stem A (Table 1). In the first rating of phase II stem A parameters (phase II A1), 22 of the 36 physicians who were re-contacted (61\%) participated. For the second re-rating of phase II stem A parameters (phase II A2), all 22 of the physicians that were re-contacted $(100 \%)$ participated. In phase II stem B, 22 of 36 physicians who were contacted $(61 \%)$ participated in the generation of physical examination parameters. All 22 of the physicians contacted $(100 \%)$ participated in the initial rating of these parameters (phase II B1), and 22 of 23 physicians contacted (96\%) participated in the final re-rating exercise (phase II B2). PH physicians from 14 cities in eight provinces across Canada were represented including physicians from Vancouver (British Columbia), Calgary and Edmonton (Alberta), Saskatoon (Saskatchewan), Winnipeg (Manitoba), London, Toronto, Hamilton, Kingston and Ottawa (Ontario), Montreal and Quebec City (Quebec), Moncton (New Brunswick) and Halifax (Nova Scotia). Collectively, this representation encompassed all major PH centres in Canada at the time of the study. The majority of the participating physicians were trained in respiratory medicine; however $\mathrm{PH}$ physicians specializing in cardiology, rheumatology and critical care medicine were also represented.

The first question of the survey was a query to determine whether the physician believed that the establishment of a predefined goaloriented approach to the management of $\mathrm{PH}$ was feasible. Of the physicians surveyed, 100\% answered 'yes'. When asked "How soon after initiation of therapy should patients be re-evaluated?" the mean response was 3.73 months for a WHO class II patient, 2.23 months for a WHO class III patient, and 1.36 months for a WHO class IV patient (Table 2). Physicians were asked whether they believed a repeat right heart catheterization (RHC) should routinely be performed after the initiation of therapy: $63 \%$ of respondents answered 'no'. Of the $37 \%$ of respondents who answered 'yes', $82 \%$ indicated that the RHC should be performed within the first six months after initiation of therapy, while $18 \%$ of respondents believed that more than six months should elapse before a repeat $\mathrm{RHC}$ is performed.

When a WHO class II patient on oral monotherapy was not regarded to have exhibited an adequate clinical response, $60 \%$ of physicians indicated that their preferred approach would be to add an additional oral agent, while $40 \%$ would prefer to switch to an alternative oral agent (Figure 1). When a WHO class III patient on oral monotherapy was not regarded to have exhibited an adequate clinical response, $97 \%$ of physicians believed that they should add - not switch - medication. Furthermore, for WHO class IV patients, 100\% of the PH physicians surveyed believed that they should not switch, 


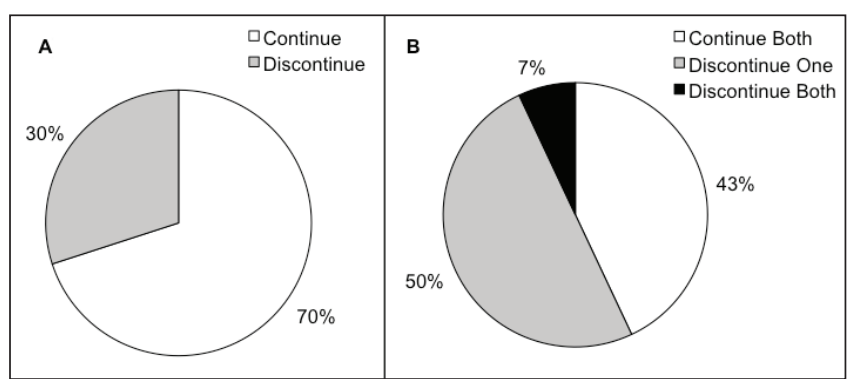

Figure 2) Survey questions 6 and 7. A "When patients on oral monotherapy are transitioned to prostacyclin therapy do you routinely continue or discontinue the oral agent?" $(n=26)$. B "When patients on oral combination therapy are transitioned to prostacyclin therapy do you routinely continue or discontinue both oral agents?" $(n=26)$

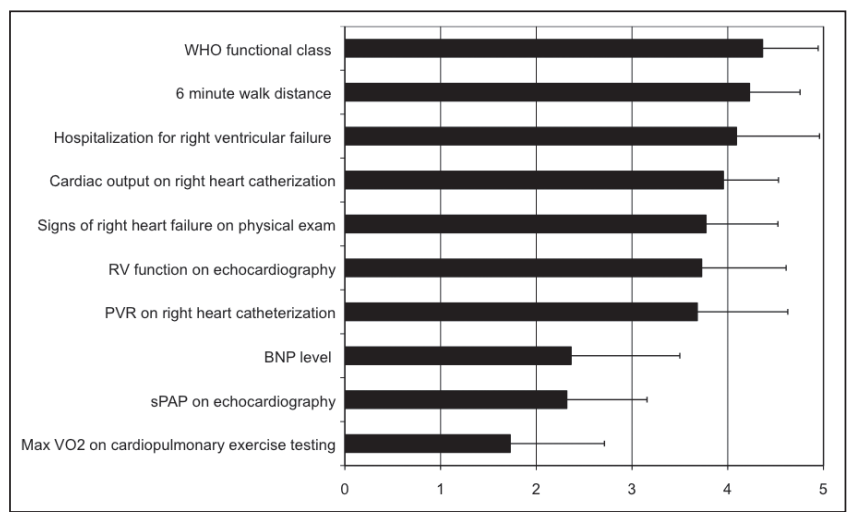

Figure 3) Phase II survey question A. "For each parameter listed below please indicate on a scale of 0 to 5 how important you think that the variable is in the determination of an adequate response to therapy (or lack of). Zero indicates that you do not think that the parameter has value in the routine re-evaluation of PH patients." ( $n=22)$. BNP B-type natriuretic peptide; exam Examination; Max $\mathrm{VO}_{2}$ Peak oxygen uptake during exercise; PVR Pulmonary vascular resistance; RV Right ventricular; sPAP Systolic pulmonary artery pressure

but add an additional oral agent to therapy (Figure 1). When patients who are on oral monotherapy are transitioned to prostacylin therapy, a majority $(70 \%)$ of physicians reported a preference to continue the oral agent in combination with the prostanoid (Figure 2A). When patients who are on oral combination therapy are transitioned to prostacylin therapy, $43 \%$ of $\mathrm{PH}$ physicians reported that they would prefer to continue both oral agents, $50 \%$ of $\mathrm{PH}$ physicians would advocate continuation of one oral agent, while only $7 \%$ of respondents said that they would discontinue both oral agents (Figure 2B).

In phase II stem $\mathrm{A}$ of the present study, participants were asked to list the parameters they believed were important to reassess after the initiation of therapy. The median number of parameters listed by the participants was four. Despite this, only 10 parameters were listed collectively (Figure 3). All participants were then provided with these 10 responses and asked to rate the importance of the parameters on a scale from 0 to 5 (Figure 3). After two rounds of questionnaires, there were three parameters with a mean score of greater than 4 (WHO functional class, 6 min walk distance [6MWD], and hospitalization for right heart failure). Four parameters had a mean score of between 3.0 and 3.9 (right ventricular dysfunction on echocardiography, cardiac output on RHC, clinical signs of right heart failure and pulmonary vascular resistance on RHC), while three parameters had mean scores of between 0 and 2.9 (systolic pulmonary artery pressure on echocardiography, B-type natriuretic peptide levels and peak oxygen uptake during exercise $\left(\max \mathrm{VO}_{2}\right)$ on cardiopulmonary exercise testing).

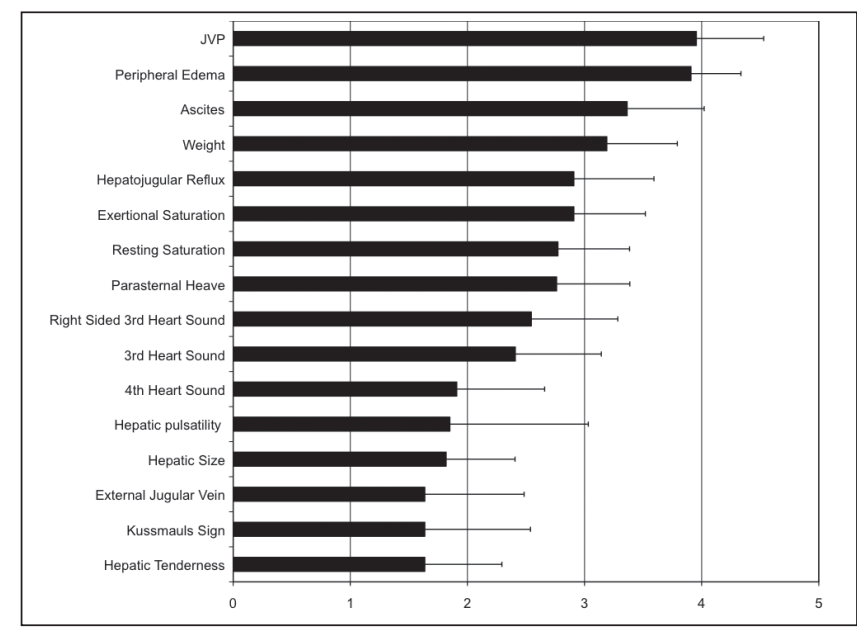

Figure 4) Phase II survey question B. "For each parameter listed below please indicate on a scale of 0 to 5 how important you think that the physical exam finding is to consider when assessing response to therapy (or lack of). Zero indicates that you do not think that the parameter has value in the routine re-evaluation of $\mathrm{PH}$ patients." $(n=22)$. JVP Jugular venous pressure

In phase II stem B of the present study, participants were asked to list physical examination parameters they considered to be important in the evaluation of patients after the initiation of therapy. Respondents described a median of three parameters yielding a collective total of 16 (Figure 4). After two rounds of rating, there were no parameters with mean scores of greater than 4. Parameters that had a mean score of greater than 3 included jugular venous pressure (JVP), peripheral edema, ascites and weight. There were six parameters with final scores of between 2.0 and 2.9 (exertional saturation, hepatojugular reflux, third heart sound, right-sided third heart sound, resting saturation and parasternal heave), and six parameters with scores of less than 2 (Kussmauls sign, hepatic size, fourth heart sound, hepatic tenderness, external jugular vein and hepatic pulsatility). Due to an error in the survey process, the parameter 'hepatic pulsatility' was only distributed once.

\section{DISCUSSION}

The present survey provided an overview of the expert opinions of Canadian PH physicians with regard to their preferred approach to IPAH patients after the initiation of therapy. The use of the Delphi technique enabled physicians to provide dynamic input with modification of their opinion based on the response of others without the negative aspects of group dynamics such as coercion or judgment. To the credit of the Canadian PH community, the response rate of our survey was very high, and participation was sustained through multiple rounds of questioning. There was complete representation of the $\mathrm{PH}$ community in Canada, with participation of physicians residing in each of the recognized Canadian PH centres. This is a reassuring indication that the survey results were an accurate reflection of opinions of physicians regarding optimal $\mathrm{PH}$ care across Canada.

Aside from calcium channel blockers, three classes of medications targeting the pulmonary vasculature are currently approved for PAH therapy: PDE5is, ERAs and prostacyclins (6). Combination therapy refers to the simultaneous use of more than one of these classes of PAHspecific therapies (usually excluding calcium channel blockers). The use of combination therapy for patients exhibiting an inadequate response to monotherapy is endorsed by several societies and $\mathrm{PH}$ treatment guidelines including the European Society of Cardiology, the European Respiratory Society, and the International Society of Heart and Lung Transplantation, as well as the 4th World Symposium on PH and the United Kingdom/Ireland PAH consensus statements $(1,6,12)$. These 
recommendations are based on a strong biological rationale for combination therapy, as well as a growing body of evidence indicating that combining PH medications is safe and effective (9). Each class of medication acts on different signalling pathways believed to be dysregulated in IPAH, and all classes have been shown to independently improve outcomes (3). However, none are curative therapies, and IPAH remains a progressive disease with a high mortality rate (13). The paradigm of simultaneously targeting multiple pathways has been successfully used in many other diseases such as hypertension, congestive heart failure and cancer. However, drug therapies for $\mathrm{PH}$ are significantly more expensive than those for more common diseases such as systemic hypertension. PDE5is and ERAs for PAH cost $\$ 10,000$ to $\$ 40,000$ per year per patient in Canada, while intravenous and subcutaneous therapies cost $\$ 80,000$ to $\$ 100,000$ per year. Therefore, the use of combination therapy for $\mathrm{PAH}$ has significant cost implications that have resulted in strict control of prescribing by government and private payers in Canada. Recent data from the Registry to EValuate Early And Long-term pulmonary arterial hypertension disease management (REVEAL), a multicentre PAH registry populated from 2006 to 2007, and containing $2525 \mathrm{PAH}$ patients, indicates that combination therapy is routinely used in the United States (14). Baseline data from the REVEAL registry found that approximately $65 \%$ of PAH patients on $\mathrm{PH}$-specific medications were being treated with combination therapy (excluding calcium channel blockers) (14). Our survey indicated that the majority of $\mathrm{PH}$ physicians in Canada support the use of combination therapy in IPAH patients who do not adequately respond to monotherapy. However, access to combination therapy is currently not available to all $\mathrm{PH}$ patients in Canada because prescription reimbursement is not universally provided by all provincial health care providers or private insurers.

With multiple PH medications to choose from and, now the possibility of combination therapy, the need to monitor disease progression and response to therapy has become more salient. From this need, the concept of goal-directed therapy has emerged - the establishment of predefined clinical targets used to make decisions regarding the maintenance and acceleration of therapy for PH. However, the optimal indicators of clinical deterioration, stability or improvement are not known with certainty. In 2005, Hoeper et al (15) published a study evaluating a protocol that incorporated three parameters as goals for therapy: 6MWD, max $\mathrm{VO}_{2}$ and peak systolic blood pressure (15). Although that study reported better outcomes when compared with historical controls, the one-, two- and three-year survival rates were not appreciatively different from those of contemporary cohorts that were not subject to the protocol of Hoeper et al $(16,17)$. The European Society of Cardiology, the European Respiratory Society, and the International Society of Heart and Lung Transplantation guidelines do not provide guidance on the specific clinical features that should be used to determine response to therapy aside from WHO functional class (1). The United Kingdom and Ireland consensus statement (12) suggested that WHO class, breathlessness, 6MWD, refractory heart failure and syncope were potential parameters to monitor and use to make therapeutic decisions. In a recent review of combination therapy, Galie et al (9) suggested that potentially useful parameters may include 6MWD, cardiac index, right atrial pressure, peak $\mathrm{VO}_{2}$, and B-type natriuretic peptide levels. However, definitive evidence that these factors are truly associated with outcomes in IPAH is lacking and the current literature is conflicting (18). In the absence of conclusive evidence for the best targets of therapy, our survey indicated that, by consensus, Canadian $\mathrm{PH}$ physicians collectively believe that only a very limited number of parameters are both prognostically important and clinically practical, with four parameters rated high (scoring between 4 and 5) and three moderate ( 3 to 4 ). Of these seven parameters, only two were indicators derived from RHC. This is important because $60 \%$ of physicians in Canada do not routinely perform repeat RHC after initiating monotherapy. The physical examination parameters that were provided by the survey respondents were more varied, with 16 parameters being listed initially. None of these parameters received a high degree of endorsement; however, there were four parameters that received moderate scores. The seven highest-rated clinical parameters (five if the patient does not undergo repeat RHC) in conjunction with the top four physical examination signs, should be considered when evaluating IPAH patients and could possibly be used as parameters to target for goal-directed therapy.

With multiple guidelines advocating the use of goal-directed therapy, but providing limited direction on how to clinically implement this approach, there is a need for experts to reach a consensus on therapeutic targets. The high response rate from Canadian PH physicians is an indication of a pervasive desire build consensus within our community in the context of the Canadian health care system to help direct and standardize care. However, consensus on the relevant clinical parameter is only one step in the development of therapy guidelines. To be clinically useful, each of these parameters will require the assignment of metrics - either cut-off or change values - that indicate a favourable or unfavourable response to therapy. With continued support from the $\mathrm{PH}$ community in Canada, it may be possible to use a similar survey technique to determine whether consensus metrics can be applied to the parameters identified in the present study.

The current study had several limitations that may also inform future directions for investigation. First, the questions and consensus from the survey do not provide any guidance with respect to what specific combinations of therapies should be considered or in what order. Second, the survey did not address the question of when to initiate monotherapy because this issue is the subject of much less debate due to greater scientific evidence. Third, our survey was intended to probe opinions about IPAH only and not other categories of PAH. Whether it is reasonable to apply the same methods of reassessment for goals of therapy to other PAH groups is unclear. As with IPAH, the precise targets for therapy in other PAH categories remains unclear.

\section{CONCLUSION}

In the absence of clear guidance from the scientific literature, gathering expert opinions and building consensus is necessary to standardize care and optimize outcomes in IPAH. Collectively, the present survey provided an overview of the opinions of Canadian PH physicians with regard to the best approach to the management of IPAH patients after the initiation of therapy. The identification of key parameters that are believed to be most important in the assessment of patients on therapy is the first step in the development of consensus guidelines and care pathways. The parameters described in the present study also highlight areas for future research and, with the worldwide push for the establishment of disease registries, identify clinically important database components for surveillance, outcome assessments and future investigation.

ACKNOWLEDGEMENTS: The authors thank Actelion Pharmaceuticals Canada Inc for assistance identifying $\mathrm{PH}$ practitioners in Canada. They thank all Canadian pulmonary hypertension experts who participated in this survey, because this survey would not have been possible without their ongoing support. They also thank Wendy Lo for preparing the web survey and managing the e-mail participation requests and responses.

CONFLICTS OF INTEREST: Adrienne Borrie has no conflicts of interest to declare. David Ostrow has received honoraria from Abbott Pharmaceuticals, Actelion Pharmaceuticals, AstraZeneca Pharmaceuticals, Bayer Pharmaceuticals and GlaxoSmithKline Pharmaceuticals for speaking engagements, as well as participation in Advisory Boards for Actelion, Pfizer/Encycive Pharmaceuticals and GSK. Robert Levy has participated in advisory and/or speaker boards for Actelion, GlaxoSmithKline, Encysive, Pfizer, Lilly and Bayer. John Swiston has received honoraria from Actelion and Pfizer/Encysive for speaking engagements as well as participation in advisory boards for GSK, Pfizer, Lilly and Actelion. Assistance for participation in educational activities has also been received from Actelion and Pfizer. 
Phase I:

\section{APPENDIX 1: PHASE I AND II SURVEY QUESTIONNAIRES}

1) Do you think that establishment of a predefined goal orientated approach to the management of pulmonary hypertension is feasible?

$\square$ Yes or $\square$ No

If no stop and do not continue with the questionnaire

2) How soon after initiation of therapy should patients be re-evaluated?

Answer in months:

3) Do you think that repeat right heart catheterization should routinely be carried out after the initiation of therapy?

$\square$ Yes or $\square$ No

4) If you answered Yes to question 3, how soon after initiation of therapy should right heat catherterization be carried out?

a $0-3$ months

a $3-6$ months

口 $>6$ months

For questions 5 through 7 assume that your local formulary rules did/do not play a role in your decision process:

5) When a patient is on oral monotherapy but is not felt to have had an adequate clinical response, would you routinely switch to an alternate oral agent or add and additional oral agent (assuming that the patient is tolerating the first drug without side effects)?
a. Class II $\square$ add or $\square$ switch
b. Class III $\square$ add or $\square$ switch
c. Class IV $\square$ add or $\square$ switch

6) When patients on oral monotherapy are transitioned to prostacylin therapy do you routinely continue or discontinue the oral agent?

$\square$ continue or $\square$ discontinue

\section{REFERENCES}

1. Galie N, Hoeper MM, Humbert M, et al. Guidelines for the diagnosis and treatment of pulmonary hypertension: The Task Force for the Diagnosis and Treatment of Pulmonary Hypertension of the European Society of Cardiology (ESC) and the European Respiratory Society (ERS), endorsed by the International Society of Heart and Lung Transplantation (ISHLT). Eur Heart J 2009;30:2493-537.

2. Morrell NW, Adnot S, Archer SL, et al. Cellular and molecular basis of pulmonary arterial hypertension. J Am Coll Cardiol 2009;54(1 Suppl):S20-31.

3. Humbert M, Sitbon O, Simonneau G. Treatment of pulmonary arterial hypertension. N Engl J Med 2004;351:1425-36.

4. Badesch DB, Champion HC, Sanchez MA, et al. Diagnosis and assessment of pulmonary arterial hypertension. J Am Coll Cardiol 2009;54(1 Suppl):S55-66.

5. Simonneau G, Robbins IM, Beghetti M, et al. Updated clinical classification of pulmonary hypertension. J Am Coll Cardiol 2009;54(1 Suppl):S43-54.

6. Barst RJ, Gibbs JS, Ghofrani HA, et al. Updated evidence-based treatment algorithm in pulmonary arterial hypertension. J Am Coll Cardiol 2009;54(1 Suppl):S78-84.

7. Gomberg-Maitland M, Olschewski H. Prostacyclin therapies for the treatment of pulmonary arterial hypertension. Eur Respir J 2008;31:891-901.

8. Dupuis J, Hoeper MM. Endothelin receptor antagonists in pulmonary arterial hypertension. Eur Respir J 2008;31:407-15.

9. Galie N, Negro L, Simonneau G. The use of combination therapy in pulmonary arterial hypertension: New developments. Eur Respir Rev 2009;18:148-53.
7) When patients on oral combination therapy are transitioned to prostacyclin therapy do you routinely continue or discontinue both oral agents?

$\square$ continue both $\square$ discontinue one $\square$ discontinue both

\section{Phase II:}

Stem A: What parameters do you think should be included as targets for goal directed therapy?

Follow up question A1: Below is a list of all responses to Stem A. For each parameter listed, indicate on a scale of 0 to 5 how important you think that the variable is in the determination of an adequate response to therapy (or lack of). Zero indicates that you do not think that the parameter has value in the routine re-evaluation of $\mathrm{PH}$ patients.

Follow up question A2: Your previous response is indicated along with the group mean and standard deviation. Please re-rate each parameter based on this information. You may provide the same response as previous or change your rating.

Stem B: For those that believe that physical examination signs are important parameters to consider, please list all findings on physical examination that you think are important. If you do not believe that physical examination signs are important, respond with "none".

Follow up question B1: Below is a list of all responses to Stem B. For each parameter listed, indicate on a scale of 0 to 5 how important you think that the variable is in the determination of an adequate response to therapy (or lack of). Zero indicates that you do not think that the parameter has value in the routine re-evaluation of $\mathrm{PH}$ patients.

Follow up question B2: Your previous response is indicated along with the group mean and standard deviation. Please re-rate each parameter based on this information. You may provide the same response as previous or change your rating.

10. Wilkins MR, Wharton J, Grimminger F, Ghofrani HA. Phosphodiesterase inhibitors for the treatment of pulmonary hypertension. Eur Respir J 2008;32:198-209.

11. Fink A, Kosecoff J, Chassin M, Brook RH. Consensus methods: Characteristics and guidelines for use. Am J Public Health 1984;74:979-83.

12. Consensus statement on the management of pulmonary hypertension in clinical practice in the UK and Ireland. Heart 2008;94(Suppl 1):i1-41.

13. Rich $\mathrm{S}$. The current treatment of pulmonary arterial hypertension: Time to redefine success. Chest 2006;130:1198-202.

14. Badesch DB, Raskob GE, Elliott CG, et al. Pulmonary arterial hypertension: Baseline characteristics from the REVEAL Registry. Chest 2010;137:376-87.

15. Hoeper MM, Markevych I, Spiekerkoetter E, Welte T, Niedermeyer J. Goal-oriented treatment and combination therapy for pulmonary arterial hypertension. Eur Respir J 2005;26:858-63.

16. McLaughlin VV, Sitbon O, Badesch DB, et al. Survival with first-line bosentan in patients with primary pulmonary hypertension. Eur Respir J 2005;25:244-9.

17. Provencher S, Sitbon O, Humbert M, Cabrol S, Jais X, Simonneau G. Long-term outcome with first-line bosentan therapy in idiopathic pulmonary arterial hypertension. Eur Heart J 2006;27:589-95.

18. Swiston JR, Johnson SR, Granton, JT. Factors that prognosticate mortality in idiopathic pulmonary arterial hypertension: A systematic review of the literature. Respir Med 2010;104:1588-607. 


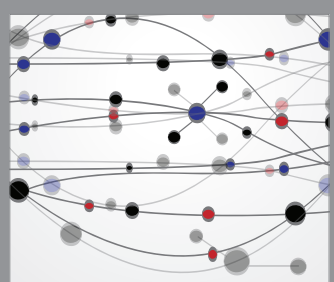

The Scientific World Journal
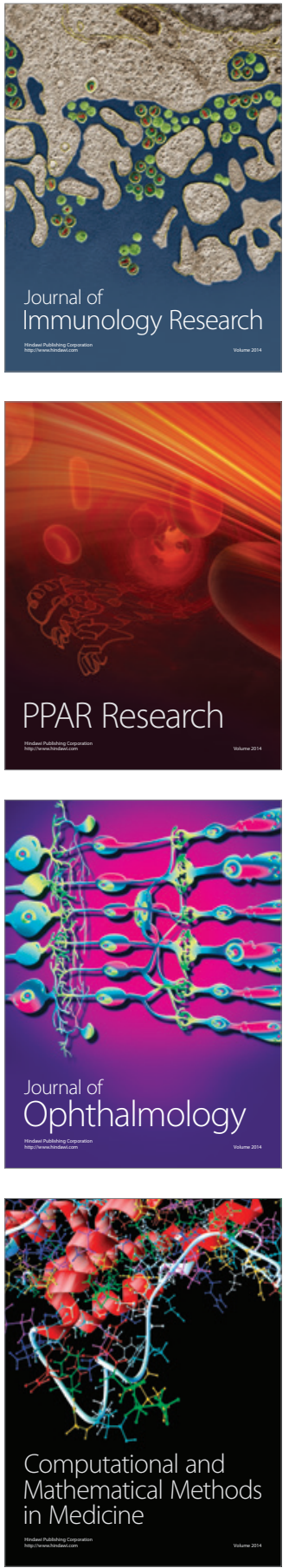

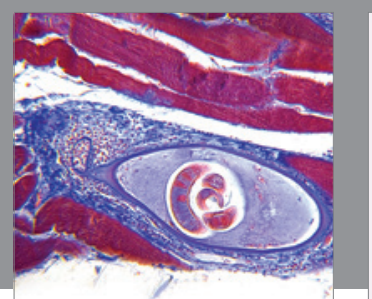

Gastroenterology Research and Practice

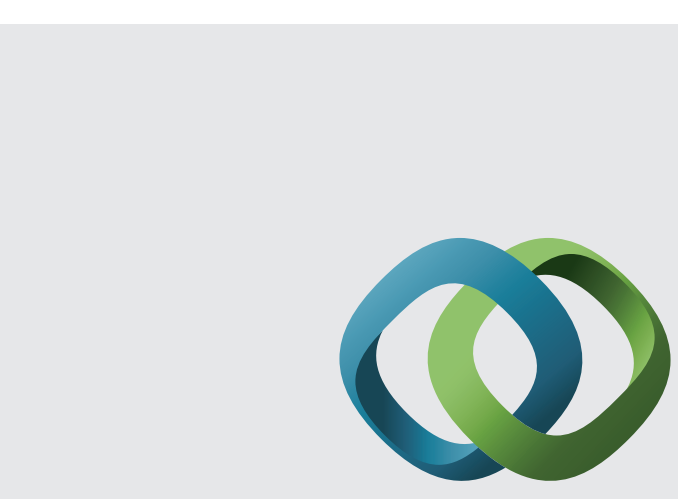

\section{Hindawi}

Submit your manuscripts at

http://www.hindawi.com
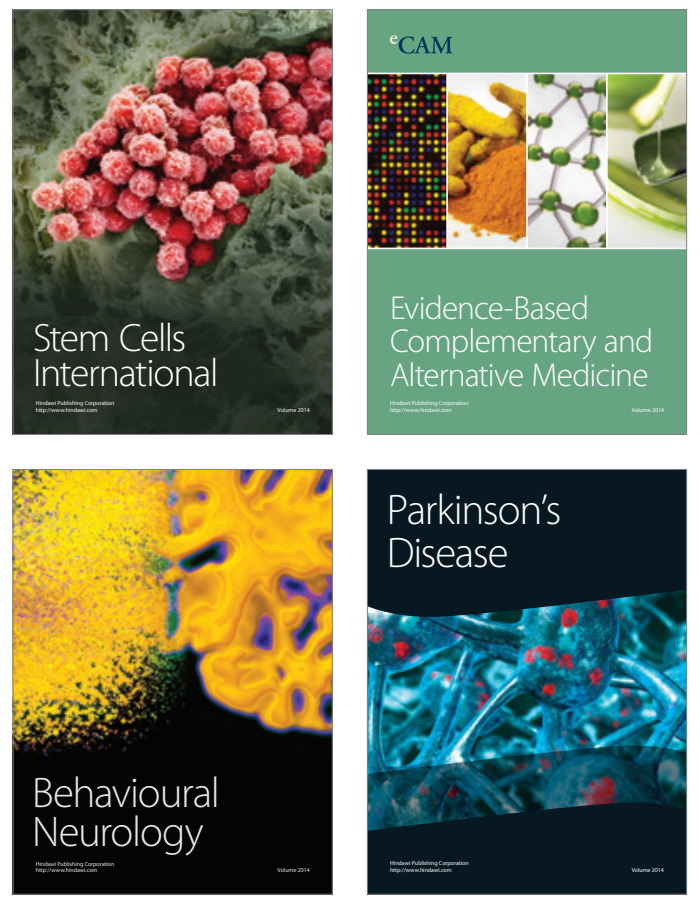
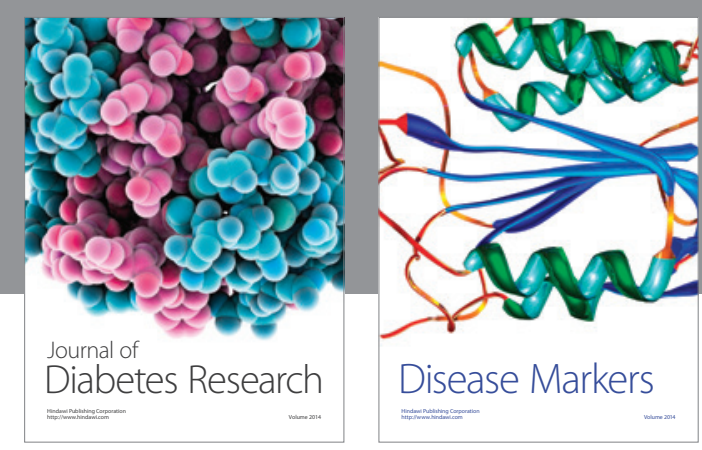

Disease Markers
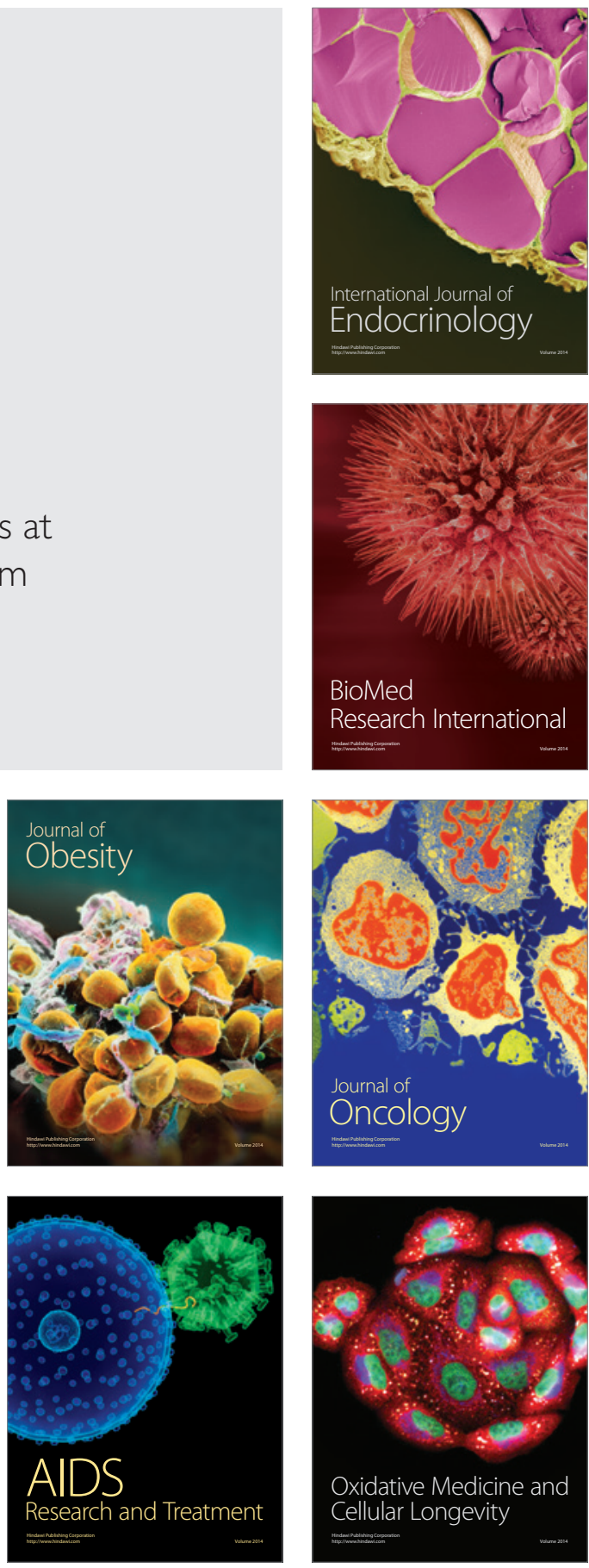